\title{
Origins of the Solar Radiation Biases over the Southern Ocean in CFMIP2 Models*
}

\author{
A. Bodas-SAlcedo, ${ }^{+}$K. D. Williams, ${ }^{+}$M. A. Ringer, ${ }^{+}$I. BeAu, ${ }^{\#}$ J. N. S. Cole, ${ }^{@}$ \\ J.-L. Dufresne, ${ }^{\&}$ T. KOSHIRO, ${ }^{* *}$ B. STEVEns, ${ }^{++}$Z. WANG, ${ }^{\# \#}$ AND T. YOKOHATA ${ }^{@ @ ~}$ \\ ${ }^{+}$Met Office Hadley Centre, Exeter, United Kingdom \\ " Météo-France, Toulouse, France \\ ${ }^{\circledR}$ Environment Canada, Toronto, Ontario, Canada \\ ${ }^{\&}$ LMD/IPSL, CNRS, Université Pierre et Marie Curie, Paris, France \\ ** Meteorological Research Institute, Japan Meteorological Agency, Tsukuba, Japan \\ ${ }^{++}$Max Planck Institute for Meteorology, Hamburg, Germany \\ \#\# Beijing Climate Center, China Meteorological Administration, Beijing, China \\ ${ }^{\circledR @ ~ N a t i o n a l ~ I n s t i t u t e ~ f o r ~ E n v i r o n m e n t a l ~ S t u d i e s, ~ T s u k u b a, ~ J a p a n ~}$
}

(Manuscript received 21 March 2013, in final form 30 July 2013)

\begin{abstract}
Current climate models generally reflect too little solar radiation over the Southern Ocean, which may be the leading cause of the prevalent sea surface temperature biases in climate models. The authors study the role of clouds on the radiation biases in atmosphere-only simulations of the Cloud Feedback Model Intercomparison Project phase 2 (CFMIP2), as clouds have a leading role in controlling the solar radiation absorbed at those latitudes. The authors composite daily data around cyclone centers in the latitude band between $40^{\circ}$ and $70^{\circ} \mathrm{S}$ during the summer. They use cloud property estimates from satellite to classify clouds into different regimes, which allow them to relate the cloud regimes and their associated radiative biases to the meteorological conditions in which they occur. The cloud regimes are defined using cloud properties retrieved using passive sensors and may suffer from the errors associated with this type of retrievals. The authors use information from the Cloud-Aerosol Lidar and Infrared Pathfinder Satellite Observations (CALIPSO) lidar to investigate in more detail the properties of the "midlevel" cloud regime. Most of the model biases occur in the cold-air side of the cyclone composite, and the cyclone composite accounts for most of the climatological error in that latitudinal band. The midlevel regime is the main contributor to reflected shortwave radiation biases. CALIPSO data show that the midlevel cloud regime is dominated by two main cloud types: cloud with tops actually at midlevel and low-level cloud. Improving the simulation of these cloud types should help reduce the biases in the simulation of the solar radiation budget in the Southern Ocean in climate models.
\end{abstract}

\section{Introduction}

The Southern Ocean plays an important role in the earth's climate. It is a region of upwelling of intermediate waters and also of formation of deep waters farther south, connecting the ocean interior with the surface (e.g., Marshall and Speer 2012). This makes it an important part of the meridional overturning circulation. As one of

\footnotetext{
* Supplemental information related to this paper is available at the Journals Online website: http://dx.doi.org/10.1175/JCLI-D-1300169.s1.

Corresponding author address: A. Bodas-Salcedo, Met Office Hadley Centre, FitzRoy Road, Exeter EX13PB, United Kingdom. E-mail: alejandro.bodas@metoffice.gov.uk
}

the few areas where the deep ocean is connected to the surface, it also plays a key role in $\mathrm{CO}_{2}$ and heat uptake (Caldeira and Duffy 2000; Kuhlbrodt and Gregory 2012). Furthermore, the details of the circulation in the Southern Ocean play a crucial role in determining the evolution of the Antarctic ice sheets and sea level (Holland et al. 2010; Bouttes et al. 2012).

Trenberth and Fasullo (2010) have recently showed that current climate models and atmospheric reanalyses have a consistent deficit of reflected shortwave radiation (RSR) at the top of the atmosphere (TOA) over the Southern Ocean. Coupled climate models also tend to show a warm sea surface temperature (SST) bias in that region, to which the excess of solar radiation entering the system at those latitudes must contribute. Trenberth and Fasullo (2010) argue that the present-day biases may 
limit the ability of models to correctly project changes under anthropogenic forcing and that some of the climate change feedbacks seen in models in the Southern Ocean may be only tenable because of the biases in the control climate. Recent studies also suggest that cloud biases over the Southern Ocean may play a major role in driving circulation and precipitation biases (Ceppi et al. 2012; Hwang and Frierson 2013). Given the role of the Southern Ocean in global climate, it is important to understand the causes of these biases. We analyze the TOA RSR biases in the Southern Ocean in the atmosphereonly models of phase 5 of the Coupled Model Intercomparison Project (CMIP5; Taylor et al. 2012). We consider atmosphere-only simulations because our main objective is to isolate the cloud radiative impact and its biases consistently in all the models. It is important to minimize errors in atmosphere-only models to facilitate their coupling with ocean models, as biases in the surface radiation budget will introduce biases in the coupled SSTs and impact the ocean heat transport in coupled models (Gleckler 2005).

Several observational studies have used the concept of "weather states" or "cloud regimes" to understand the influence of clouds in the earth's radiation budget. The approach uses cloud properties from the International Satellite Cloud Climatology Project (ISCCP; Rossow and Schiffer 1999) to define a set of classes or regimes and then uses conditional sampling to study the influence of each regime in the radiation budget. Jakob and Tselioudis (2003) and Rossow et al. (2005) use this approach over the tropics to understand the interaction of the regimes with the large-scale circulation and the variations in the tropical climate. Tselioudis and Rossow (2011) study the time scales of variability of the tropical atmosphere derived from weather states. Oreopoulos and Rossow (2011) divide the globe into the tropics, northern midlatitudes, and southern midlatitudes and analyze the impact of ISCCP cloud regimes in the TOA and surface atmospheric budget. Haynes et al. (2011) focus on the Southern Ocean; they composite vertical profiles from active instruments onboard the A-Train (Stephens et al. 2002) to provide the vertical structure of clouds in each regime. They conclude that low-cloud regimes, due to their high frequency of occurrence, dominate the shortwave cloud effects at the TOA and at the surface over the Southern Ocean. Tselioudis et al. (2013) also use A-Train data to study the vertical distribution of clouds within ISCCP weather states globally.

The concept of cloud regimes has also been used to assess the performance of climate models. Williams and Tselioudis (2007) apply a clustering technique to define cloud regimes in three distinct regions (tropics, ice-free extratropics, and ice-covered regions) and assess the simulation of the cloud regimes in six climate models. Williams and Webb (2009) simplify the method for assigning model data to observed cloud regimes. They show that a too low frequency of the bright midlevel-top cloud regime in the midlatitude oceans contributes to a too weak shortwave cloud radiative effect (CRE) in models. Tsushima et al. (2013) apply the Williams and Webb (2009) method to study the seasonal variation of the total cloud radiative effect in each regime, both in the observations and in several climate models.

Another approach that has been widely used for understanding the role of clouds in the midlatitudes is cyclone compositing. Although the definitions of cyclones and the algorithms used to identify them vary, this technique fundamentally implies calculating mean fields after conditional sampling around cyclone centers. Bauer and Del Genio (2006) composite winter midlatitude cyclones in a climate model and conclude that it underestimates the cyclone ageostrophic circulation. Field and Wood (2007) examine the composite cloud, precipitation, and surface wind structure of midlatitude cyclones and study its dependence on cyclone strength and atmospheric moisture. Field et al. (2008) use that technique to assess the impact of a new microphysical parameterization scheme in a climate model. Field et al. (2011) extend it to compare cyclone composites of vertical profiles of cloud and precipitation in the Met Office's global weather forecast model with CloudSat observations. They show that the biases in the vertical distribution of cloud fraction depend more on the cyclone strength than on its moisture and show that the forecast model tends to underestimate the TOA reflected flux on the cold-air side of the cyclone. Williams et al. (2013) apply cyclone compositing techniques to analyze how cloud and radiation biases over the Southern Ocean develop in climate models run in "weather forecast mode."

Bodas-Salcedo et al. (2012) merge the cloud regime and cyclone compositing techniques to study the role of clouds in the Southern Ocean shortwave bias in the latest version of the atmosphere-only version of the Met Office model. This allows them to relate the observed radiative biases in the cloud regimes with the meteorological conditions in which they occur. They focus their analysis on cyclonic conditions, but they do not study the role of noncyclonic conditions. We extend that methodology here to provide insights in to the biases in solar radiation over the Southern Ocean in the latest generation of climate models. In particular, we calculate the contribution of cyclonic and noncyclonic conditions to the climatological RSR, allowing us to assess their relative importance in the climatological biases observed in models. Section 2 describes the methodology and the 
data used. Section 3 presents a climatological overview of the RSR biases in the CMIP5 ensemble of atmosphere-only models. Then, section 4 presents the results of the cyclone composite for a subset of models and looks at the role of cyclones in the RSR climatological biases. Section 5 separates the radiation biases within the cyclone composite in cloud regimes, and section 6 uses information from the Cloud-Aerosol Lidar and Infrared Pathfinder Satellite Observations (CALIPSO) lidar to understand the vertical structure of clouds in the regime that dominates the radiative errors across models. Section 7 summarizes the results and discusses future work.

\section{Methodology, models, and observations}

Here we apply the methodology of Bodas-Salcedo et al. (2012), which combines the clustering methodology developed by Williams and Webb (2009) and the cyclone compositing from Field and Wood (2007). Williams and Webb (2009) obtain seven midlatitude cloud regimes by spatiotemporal clustering of dailymean ISCCP histograms of cloud-top pressure (CTP) versus cloud optical thickness $\tau$. The mean cloud albedo $\alpha$, CTP, and cloud fraction (CF) are obtained for these regimes. Daily-mean $\alpha, \mathrm{CTP}$, and $\mathrm{CF}$ are then used to assign model grid points to one of seven cloud regimes. These regimes are called shallow cumulus, cumulusstratocumulus transition, stratocumulus, midlevel, frontal, cirrus, and thin cirrus. The names are intended to indicate the typical characteristics of the majority of cloud that makes up the regime. We composite the results around cyclone centers following Field and Wood (2007) over the latitudes $40^{\circ}-70^{\circ} \mathrm{S}$. Bodas-Salcedo et al. (2012) use a constant longitude-latitude rectangle to composite the cyclones. We follow the original method of Field and Wood (2007), and composite the cyclones in an area-conserving grid. For each cyclone, all the necessary variables are regridded onto a 4000 by $4000 \mathrm{~km}^{2}$ domain, with origin on the cyclone center. Only points within a 2000-km distance are kept in the composite. We use area-weighted gridding for all variables, except for the cloud regime classification, for which we use the nearest neighbor method. This is required to maintain the discrete nature of the cloud regime data. The cyclone centers are identified by finding minima in daily-mean sea level pressure. Then, the relative frequency of occurrence (RFO) of each regime at each grid box around the cyclone center is found. This allows us to identify the typical synoptic conditions in which the cloud regime biases occur. This could be potentially used to develop hypotheses of model changes that target the meteorological conditions that prevail in those regions of the cyclones that are mostly responsible for the radiation bias, as shown by Bodas-Salcedo et al. (2012). As the focus of this paper is to study the solar radiation biases over the Southern Ocean in climate models, we restrict our analysis to the summer months of December, January, and February.

We use daily-mean cloud retrievals ( $\alpha$, CTP, and CF) from the D1 series of the ISCCP database (Rossow and Schiffer 1999) and daily-mean radiative fluxes from Clouds and the Earth's Radiant Energy System (CERES) SYN1deg-Day_Ed2.6 dataset (Wielicki et al. 1996). Daily-mean TOA radiative fluxes from the ISCCP flux data (FD) dataset (Zhang et al. 2004) are used as a second data source, to provide an estimate of the observational uncertainty. We use CERES as preferred dataset because it is a more direct measurement of the TOA fluxes, and it also uses a better scene identification from the Moderate Resolution Imaging Spectroradiometer, better calibration and stability of the satellite instruments over time, and other advantages (Wielicki et al. 1996; Loeb et al. 2009). We also use the 10-yr monthly climatology of TOA radiative fluxes from the CERES Energy Balanced and Filled (EBAF) Ed2.6r dataset (Loeb et al. 2009). We use daily-mean sea level pressure from ERA-Interim (Dee et al. 2011) as the observational dataset for the identification of cyclone centers. We also use data from the Cloud-Aerosol Lidar with Orthogonal Polarization (CALIOP) onboard CALIPSO (Winker et al. 2009). In particular, we use the GCM-Oriented CALIPSO Cloud Product (GOCCP; Chepfer et al. 2010).

Model data are obtained from the Atmospheric Model Intercomparison Project (AMIP) experiment of the CMIP5 archive. Table 1 shows the list of models that had submitted data from the AMIP experiment to the CMIP5 archive at the time of conducting this study (including expanded names for these models). These models are used to provide an overview of the climatological biases in a relatively large ensemble of models in section 3. The Cloud Feedback Model Intercomparison Project phase 2 (CFMIP2), which is part of CMIP5, requests additional diagnostics to be produced from a subset of the CMIP5 experiments. In particular, it requests diagnostics from the CFMIP Observational Simulator Package (COSP; Bodas-Salcedo et al. 2011), which are comparable to the ones provided by the observational datasets. In the analysis presented in this paper, we use the ISCCP simulator in COSP (Klein and Jakob 1999; Webb et al. 2001).

\section{Climatological bias of the CMIP5 AMIP ensemble}

Figure 1 shows the December-February (DJF) RSR climatology over the Southern Hemisphere from the CERES-EBAF observations (top left) and the model 
TABLE 1. Models used in this study.

\begin{tabular}{|c|c|c|c|}
\hline Model & Model expansion & Institution & References \\
\hline BCC-CSM1.1-M & $\begin{array}{l}\text { Beijing Climate Center (BCC), Climate } \\
\text { System Model, version } 1.1 \text { (moderate } \\
\text { resolution) }\end{array}$ & $\begin{array}{l}\text { BCC, China Meteorological } \\
\text { Administration, Beijing, China }\end{array}$ & Wu et al. 2010 \\
\hline CanAM4 & $\begin{array}{l}\text { Fourth-generation AGCM of the Canadian } \\
\text { Centre for Climate Modelling and Analysis } \\
\text { (CCCma) }\end{array}$ & $\begin{array}{l}\text { CCCma, Victoria, British Columbia, } \\
\text { Canada }\end{array}$ & von Salzen et al. 2013 \\
\hline CCSM4 & Community Climate System Model, version 4 & $\begin{array}{l}\text { National Center for Atmospheric } \\
\text { Research (NCAR), Boulder, } \\
\text { Colorado, United States }\end{array}$ & Gent et al. 2011 \\
\hline $\begin{array}{l}\text { CNRM-CM5 } \\
\text { (atmospheric } \\
\text { component: } \\
\text { ARPEGE v5.2) }\end{array}$ & $\begin{array}{l}\text { Centre National de Recherches } \\
\text { Météorologiques (CNRM) Coupled } \\
\text { Global Climate Model, version } 5 \\
\text { (atmospheric component: } \\
\text { Action de Recherche Petite Echelle } \\
\text { Grande Echelle, version 5.2) }\end{array}$ & $\begin{array}{l}\text { CNRM, Météo-France and Centre } \\
\text { Européen de Recherches et de } \\
\text { Formation Avancée en Calcul } \\
\text { Scientifique (CERFACS), } \\
\text { Toulouse, France }\end{array}$ & Voldoire et al. 2013 \\
\hline CSIRO Mk3.6.0 & $\begin{array}{l}\text { Commonwealth Scientific and Industrial } \\
\text { Research Organisation (CSIRO) Mark, } \\
\text { version 3.6.0 }\end{array}$ & $\begin{array}{l}\text { CSIRO Marine and Atmospheric } \\
\text { Research, Melbourne, in collaboration } \\
\text { with the Queensland Climate } \\
\text { Change Centre of Excellence } \\
\text { (QCCCE), Brisbane, Australia }\end{array}$ & Rotstayn et al. 2010 \\
\hline ERA-Interim & $\begin{array}{l}\text { European Centre for Medium-Range } \\
\text { Weather Forecasts (ECMWF) Interim } \\
\text { Re-Analysis }\end{array}$ & ECMWF, Reading, United Kingdom & Dee et al. 2011 \\
\hline FGOALS-s2 & $\begin{array}{l}\text { Flexible Global Ocean-Atmosphere-Land } \\
\text { System Model gridpoint, second spectral } \\
\text { version }\end{array}$ & $\begin{array}{l}\text { State Key Laboratory of Numerical } \\
\text { Modeling for Atmospheric Sciences } \\
\text { and Geophysical Fluid Dynamics } \\
\text { (LASG), Institute of Atmospheric } \\
\text { Physics (IAP), the Chinese Academy } \\
\text { of Sciences (CAS), Beijing, China }\end{array}$ & \\
\hline GFDL-HIRAM-C180 & $\begin{array}{l}\text { Geophysical Fluid Dynamics Laboratory } \\
\text { (GFDL) High Resolution Atmospheric } \\
\text { Model, C180 resolution }\end{array}$ & $\begin{array}{l}\text { GFDL, Princeton, New Jersey, United } \\
\text { States }\end{array}$ & \\
\hline GFDL-HIRAM-C360 & $\begin{array}{l}\text { GFDL High Resolution Atmospheric Model, } \\
\text { C360 resolution }\end{array}$ & $\begin{array}{l}\text { GFDL, Princeton, New Jersey, United } \\
\text { States }\end{array}$ & \\
\hline GISS-E2-R & $\begin{array}{l}\text { Goddard Institute for Space Studies } \\
\text { (GISS) Model E2, coupled with the Russell } \\
\text { ocean model }\end{array}$ & $\begin{array}{l}\text { National Aeronautics and Space } \\
\text { Administration (NASA) GISS, New } \\
\text { York, New York, United States }\end{array}$ & \\
\hline HadGEM2-A & $\begin{array}{l}\text { Hadley Centre Global Environment Model, } \\
\text { version } 2 \text {-Atmosphere }\end{array}$ & $\begin{array}{l}\text { Met Office Hadley Centre, Exeter, } \\
\text { United Kingdom }\end{array}$ & $\begin{array}{l}\text { Collins et al. 2011; } \\
\text { Martin et al. 2011 }\end{array}$ \\
\hline INM-CM4.0 & $\begin{array}{l}\text { Institute of Numerical Mathematics (INM) } \\
\text { Coupled Model, version } 4.0\end{array}$ & INM, Moscow, Russia & Volodin et al. 2010 \\
\hline IPSL-CM5A-LR & $\begin{array}{l}\text { L'Institut Pierre-Simon Laplace (IPSL) } \\
\text { Coupled Model, version 5A, low resolution }\end{array}$ & IPSL, Paris, France & Hourdin et al. 2013a \\
\hline IPSL-CM5A-MR & $\begin{array}{l}\text { IPSL Coupled Model, version 5A, mid } \\
\text { resolution }\end{array}$ & IPSL, Paris, France & Hourdin et al. 2013a \\
\hline IPSL-CM5B-LR & $\begin{array}{l}\text { IPSL Coupled Model, version 5B, low } \\
\text { resolution }\end{array}$ & IPSL, Paris, France & Hourdin et al. 2013b \\
\hline MIROC5 & $\begin{array}{l}\text { Model for Interdisciplinary Research on } \\
\text { Climate, version } 5\end{array}$ & $\begin{array}{l}\text { Atmosphere and Ocean Research } \\
\text { Institute (AORI), The University } \\
\text { of Tokyo, Chiba; National Institute } \\
\text { for Environmental Studies (NIES), } \\
\text { Ibaraki; and Japan Agency for } \\
\text { Marine-Earth Science and Technol- } \\
\text { ogy, (JAMSTEC), Kanagawa, Japan }\end{array}$ & Watanabe et al. 2010 \\
\hline MPI-ESM-LR & $\begin{array}{l}\text { Max Planck Institute (MPI) Earth System } \\
\text { Model, low resolution }\end{array}$ & $\begin{array}{l}\text { Max Planck Institute for Meteorology, } \\
\text { Hamburg, Germany }\end{array}$ & \\
\hline MPI-ESM-MR & $\begin{array}{l}\text { MPI Earth System Model, } \\
\text { medium resolution }\end{array}$ & $\begin{array}{l}\text { Max Planck Institute for Meteorology, } \\
\text { Hamburg, Germany }\end{array}$ & \\
\hline
\end{tabular}


TABLE 1. (Continued)

\begin{tabular}{|c|c|c|c|}
\hline Model & Model expansion & Institution & References \\
\hline MRI-AGCM3.2H & $\begin{array}{l}\text { Meteorological Research Institute (MRI) } \\
\text { Atmospheric General Circulation Model, } \\
\text { version 3.2, 60-km resolution }\end{array}$ & MRI, Tsukuba, Japan & Mizuta et al. 2012 \\
\hline MRI-AGCM3.2S & $\begin{array}{l}\text { MRI Atmospheric General } \\
\text { Circulation Model, version 3.2, 20-km } \\
\text { resolution }\end{array}$ & MRI, Tsukuba, Japan & Mizuta et al. 2012 \\
\hline MRI-CGCM3 & $\begin{array}{l}\text { MRI Coupled Atmosphere-Ocean } \\
\text { General Circulation } \\
\text { Model, version } 3\end{array}$ & MRI, Tsukuba, Japan & Yukimoto et al. 2011 \\
\hline NorESM1-M & $\begin{array}{l}\text { Norwegian Earth System Model, } \\
\text { version } 1 \text { (intermediate resolution) }\end{array}$ & Norwegian Climate Centre, Norway & \\
\hline
\end{tabular}

differences from it. The ERA-Interim and the observational estimates from ISCCP-FD are also included as additional models. Out of 22 models, 16 (including ERA-Interim) show moderate/strong negative biases in RSR south of $40^{\circ} \mathrm{S}, 2$ show a mixed pattern or small biases [BCC-CSM1.1-M and NorESM1-M], and 3 show a strong positive bias (IPSL models). This suggests that most models underestimate the RSR in the Southern Ocean, consistent with Trenberth and Fasullo (2010). However, there is a substantial spread within the ensemble in that region, as shown in the zonal-mean plot in Fig. 2. This is consistent with the behavior of a fivemember multimodel ensemble run in forecast mode for the transpose-AMIP phase 2 experiment (T-AMIP2; Williams et al. 2013), implying that these biases develop quickly during the first few days of evolution in most models. ERA-Interim shows similar errors to other models, which reinforces the idea that a large fraction of the climatological error comes from the parameterization of the local physics, rather than having a dynamical origin (Williams and Brooks 2008; Su et al. 2013). This also suggests that deviations in air-sea interactions in AMIP runs from those in coupled runs do not play a major role in this analysis. It is worth mentioning that ISCCP-FD shows a high bias with respect to CERES. If ISCCP-FD were used as the observational reference, rather than CERES, then the models low biases would be larger. Models consistently overestimate the clearsky RSR in the Southern Hemisphere up to $70^{\circ} \mathrm{S}$ (not shown), so clear-sky fluxes tend to partially mitigate the observed negative RSR bias.

At the time of conducting this study, the following 10 models had submitted daily diagnostics required to conduct the cyclone compositing and clustering analysis: BCC-CSM1.1-M, CanAM4, CNRM-CM5, IPSL-CM5ALR, IPSL-CM5A-MR, IPSL-CM5B-LR, HadGEM2-A, MIROC5, MPI-ESM-LR, and MRI-CGCM3. We focus only on these models for the rest of the paper.

\section{Cyclone compositing}

Figure 3 shows the DJF-mean cyclone composites of RSR over the Southern Ocean $\left(40^{\circ}-70^{\circ} \mathrm{S}\right)$. These composites have been constructed from daily data from the months of December, January, and February from 2002 to 2007, for both the models and the observations. We have repeated the analysis with only $3 \mathrm{yr}$ of data, and the results are almost identical, suggesting that the impact of interannual variability is very small. Of course, a longer time series may be needed if this methodology is applied to coupled model data. We restrict the analysis presented in this section and in section 5 to ice-free ocean points only, where the satellite cloud retrievals are more reliable. This ensures that the impact of errors in the satellite cloud retrievals is minimized when we classify the data into cloud regimes in section 5 . The cyclone composite domain axes range from -2000 to $2000 \mathrm{~km}$. The orientation of these plots is such that negative (positive) $y$ values define the poleward (equatorward) side of the cyclone. The schematic in Fig. $3 \mathrm{a} 2$ shows the typical position of the fronts in this frame of reference, consistent with the observational analysis of Govekar et al. (2011). The frontal region, a region of large-scale ascent (Bauer and Del Genio 2006), is dominated by high, thick, and highly reflective cloud with larger values of RSR and typically lies in the northeast quadrant. Bauer and Del Genio (2006) show that the cold-air sector behind the cold front is a region of large-scale subsidence. This subsidence is relatively strong just behind the cold front and weak or close to neutral in the rest of the cold-air sector. In most models, this cold-air sector is dominated by a smaller cloud coverage and less reflective clouds, and hence the RSR is significantly lower than in the frontal region. All models analyzed conform to this picture to a certain degree. Models generally show a similar spatial pattern in the bias, with high bias (or less negative) in the frontal region and low bias 

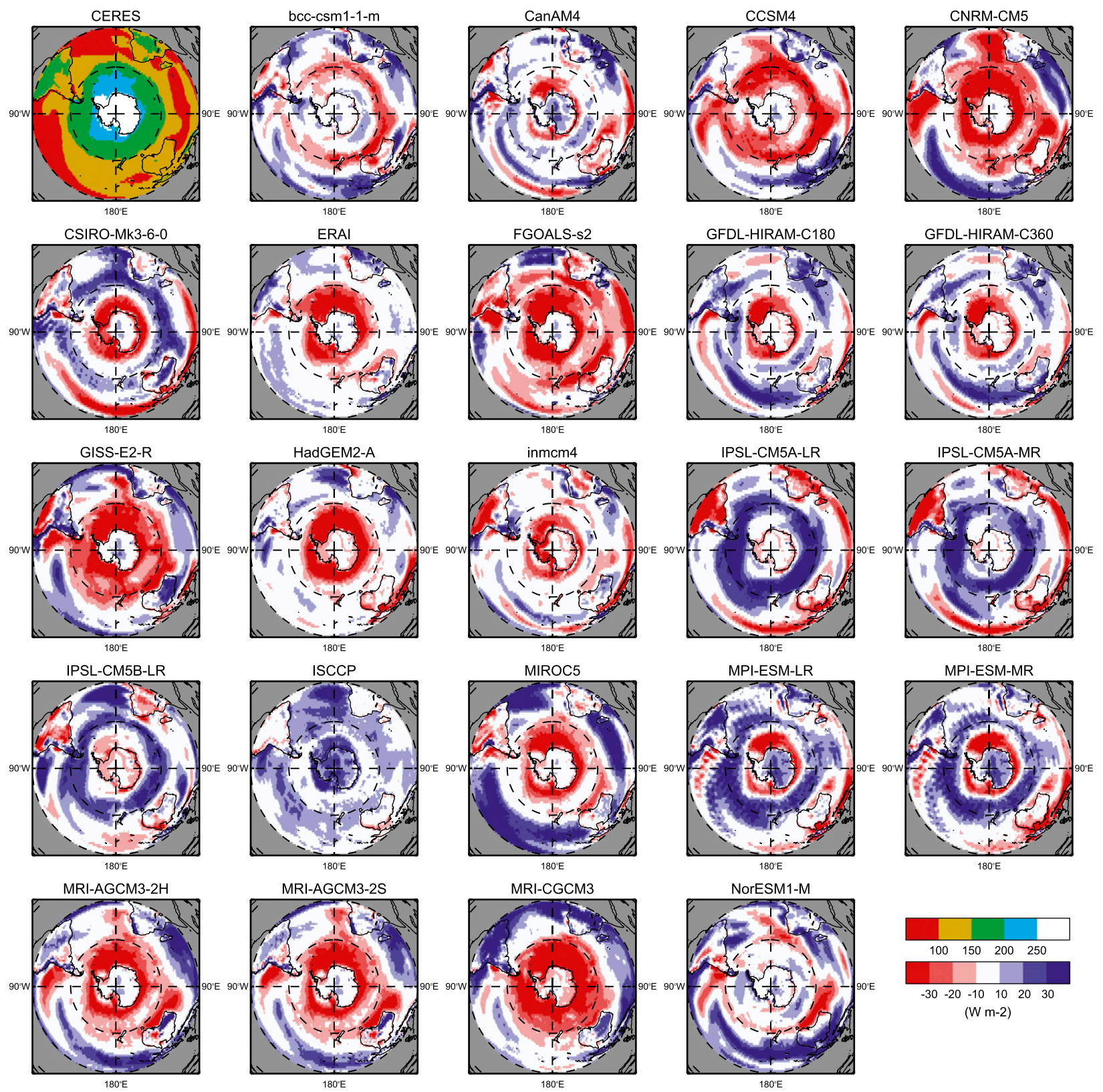

$(\mathrm{W} \mathrm{m}-2)$

FIG. 1. Southern Hemisphere DJF climatology of TOA reflected shortwave radiation. (top left) CERES-EBAF observations. All other panels show the model biases with respect to CERES. ISCCP-FD is also shown as an additional model.

(or less positive) in the cold-air and poleward sides of the composite. This subset of models shows both low and high average RSR biases for the cyclone composite. This somewhat contrasts with the results shown in Fig. 1, where the majority of models show low RSR climatological biases. The reason for this is that the subset of models analyzed here contains the four models (IPSL and MPI models) of the entire ensemble that show a high RSR bias, which should be borne in mind in the analysis presented below.
The correlation between the bias in the cold-air side of the cyclone composite and the DJF climatological error is very high (Fig. 4). The cold-air side of the cyclone is defined roughly as the second and third quadrants composite domain, using the standard trigonometric definition (see Fig. 3a2). However, this correlation does not tell how much of the climatological bias in the $40^{\circ}-70^{\circ} \mathrm{S}$ region is due to the error in the cyclone composite. Table 2 decomposes the climatological error in the $40^{\circ}-70^{\circ} \mathrm{S}$ band into cyclonic and noncyclonic 


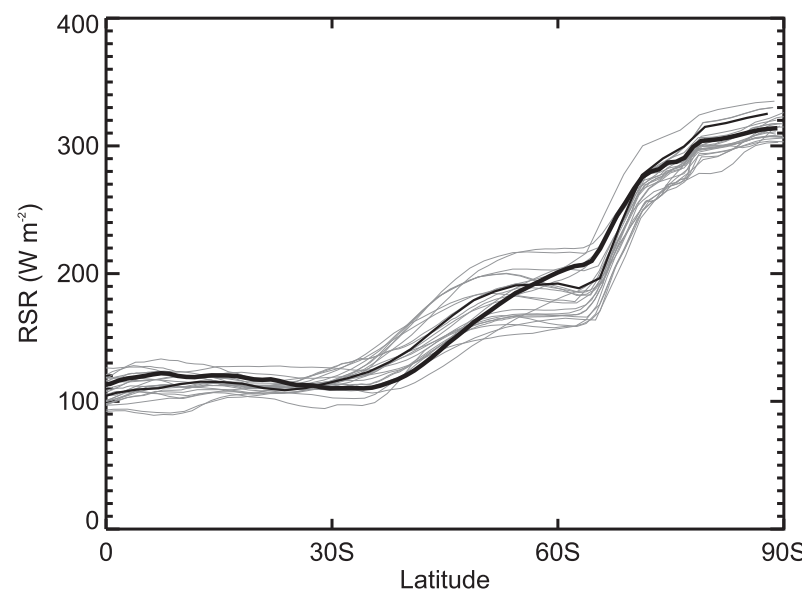

FIG. 2. Zonal mean of the Southern Hemisphere DJF climatology of TOA upwelling shortwave radiation. CERES is the thick black line, ISCCP is the thin black line, and the models are the thin gray lines.

contributions. Noncyclonic conditions are simply defined as those points not included in the cyclone composite. Cyclonic points occupy $54 \%$ of the $40^{\circ}-70^{\circ} \mathrm{S}$ latitude band in ERA-Interim, with models showing similar values (column 2). Generally, models show both negative and positive RSR biases around cyclone centers (column 3), consistent with the results from Fig. 3. The fourth column shows the absolute contribution of the bias in the composite cyclone to the climatological bias. The ensemble-mean contribution is $-1 \mathrm{~W} \mathrm{~m}^{-2}$, with models typically showing strong RSR biases, positive or negative. Columns 5-7 of this table show the same statistics but for the "noncyclonic" area. The frequency of occurrence (column 4) is complementary to the area occupied by the cyclones, as the domain is fully sampled. The ensemble-mean contribution to the climatological bias from noncyclonic areas is $1 \mathrm{~W} \mathrm{~m}^{-2}$, so on average this subset of models is unbiased with respect to the observations in the region $40^{\circ}-70^{\circ} \mathrm{S}$.

Figure 5 shows the latitudinal dependence of the quantities in Table 2. Cyclonic grid boxes show a large contribution to the low climatological bias south of $55^{\circ} \mathrm{S}$ (Fig. 5c). Models do not show such a large contribution to the climatological bias from noncyclonic grid points at any latitude (Fig. 5f), even though the RSR is also substantially underestimated in noncyclonic grid points south of $55^{\circ} \mathrm{S}$ (Fig. 5e). The reason for this being that the area occupied by cyclonic grid boxes south of $50^{\circ} \mathrm{S}$ is small. In those models that show a climatological low bias, arguably more representative of the whole ensemble of CMIP5 models, these results show that the cyclonic areas are the leading contributors to the climatological errors.

\section{Radiative impact of cloud regimes in cyclonic conditions}

Having established that the climatological biases are mostly attributable to cyclonic grid points, we classify the cyclonic grid points into seven cloud regimes, using the methodology of Williams and Webb (2009). Data from IPSL-CM5A-LR and IPSL-CM5A-MR are not used because of problems in the implementation of the ISCCP simulator in these models. As in the previous section, we use daily data from the months of December, January, and February from 2002 to 2007, for both the models and the observations.

To relate the radiative biases to errors in the representation of the different cloud regimes, we compute the mean contribution of each cloud regime to the total error in RSR (model minus CERES) in the cyclone composite domain, as shown by the diamonds in Fig. 6 . For each regime, we also split the error into contributions from errors in the relative frequency of occurrence, the radiative properties of the regime when simulated, and a covariation term, following Williams and Webb (2009). There is a considerable consistency among model biases in most of the regimes. The midlevel regime contributes most to the deficit in RSR, with some contribution from the cirrus regime. Most models partly compensate this deficit by producing too much frontal and low-level cloud regimes. The errors in the thin cirrus regime are small, which is not surprising because these clouds have little impact on shortwave radiation. Across all the regimes, the error in the frequency of occurrence is the dominant term, with a significant contribution from errors in radiative properties only in the midlevel regime. ISCCP-FD (leftmost bar in each regime in Fig. 6) shows very small and generally positive errors with respect to CERES in all clusters. The consistency in the RSR between these datasets is quite remarkable. Not only do the climatological values agree quite well (with ISCCP-FD slightly biased high), but there are no large regime-dependent biases either. Figure 6 also includes clear sky as an additional regime. The clear-sky contribution to the error is negligible in all models but MRICGCM3. MRI-CGCM3 is the only model that produces a significant amount of clear-sky grid boxes (daily means at $2.5^{\circ}$ resolution) in the cyclone composite domain.

To check whether the mean cluster contributions shown in Fig. 6 are representative of the entire composite domain, we obtain the cloud regime with the largest contribution to the total RSR error for each grid box in the composite domain (Fig. 7). The midlevel cloud regime is the dominant source of errors in most areas of the cyclone composite for all models, with the frontal cloud regime often dominating the frontal region 


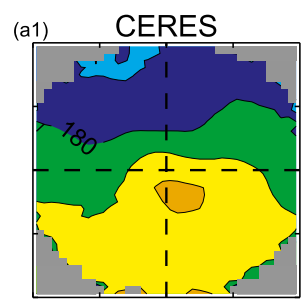

(a2)

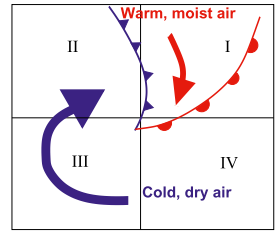

(e1) CNRM-CM5

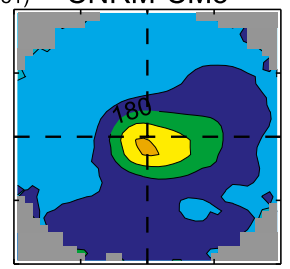

(e2)

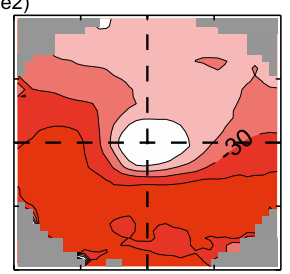

(i1) IPSL-CM5B-LR

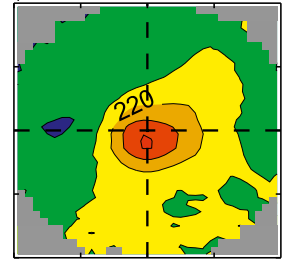

(i2)

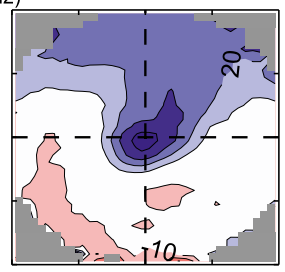

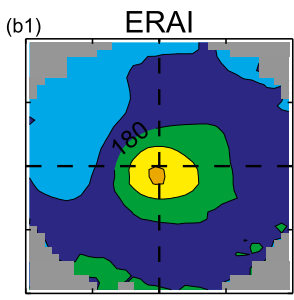

(b2)
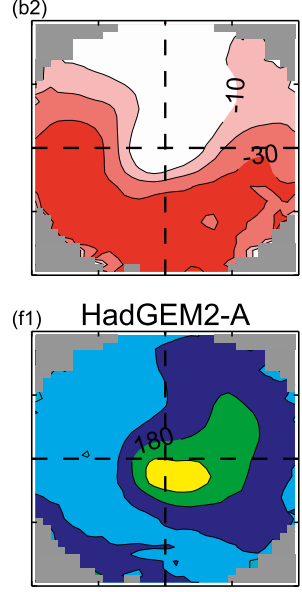

(f2)
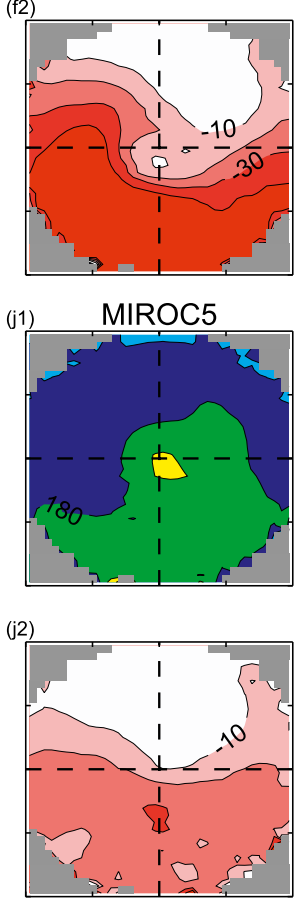

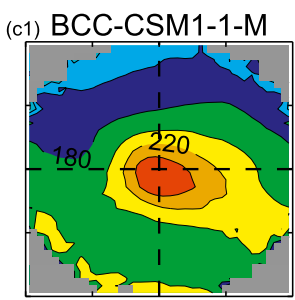

(c2)

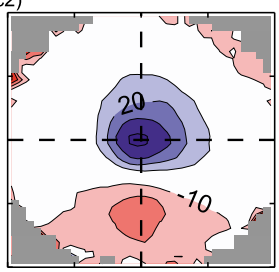

(g1) IPSL-CM5A-LR

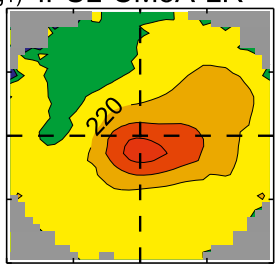

(g2)

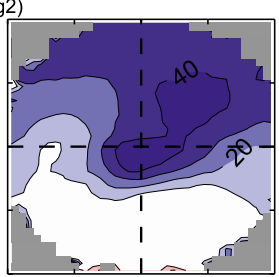

(k1) MPI-ESM-LR

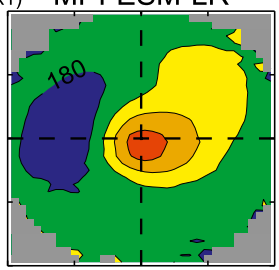

(k2)

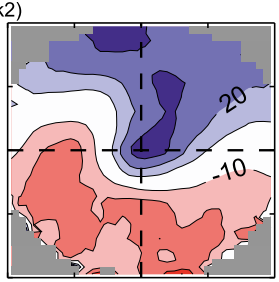

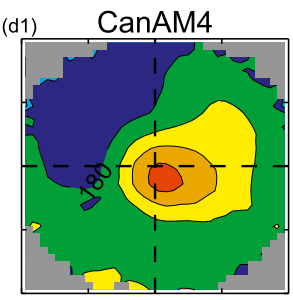

(d2)

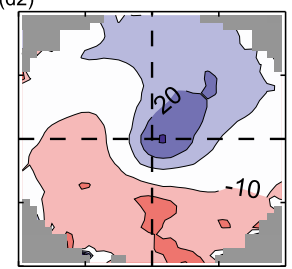

(h1) IPSL-CM5A-MR

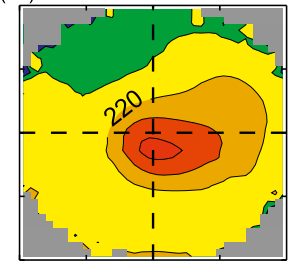

(h2)
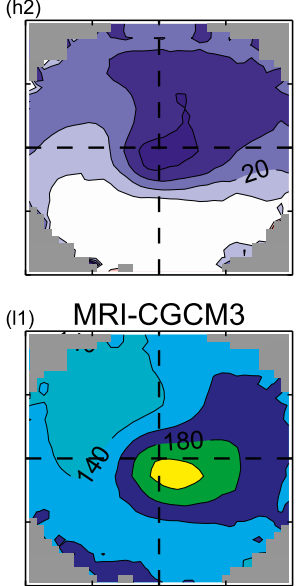

(I2)

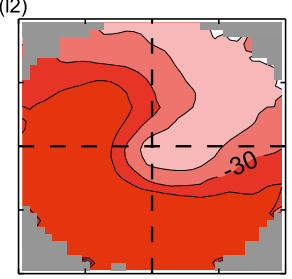

120140160180200220240260

$\begin{array}{llllllll}-40 & -30 & -20 & -10 & 10 & 20 & 30 & 40\end{array}$

FIG. 3. Composites of TOA reflected shortwave radiation $\left(\mathrm{W} \mathrm{m}^{-2}\right)$ around cyclone centers over the Southern Ocean $\left(40^{\circ}-70^{\circ} \mathrm{S}\right)$. (a1)-(d1),(e1)-(h1),(i1)-(11) The average composite for each model: mean values. (a2)-(d2),(e2)-(h2),(i2)-(12) The difference plots with respect to CERES radiative fluxes (model minus observations). The schematic in (a2) shows the typical position of the fronts in this frame of reference and the convention used to enumerate the quadrants in the composite. The $x$ and $y$ axes range from -2000 to $2000 \mathrm{~km}$. 


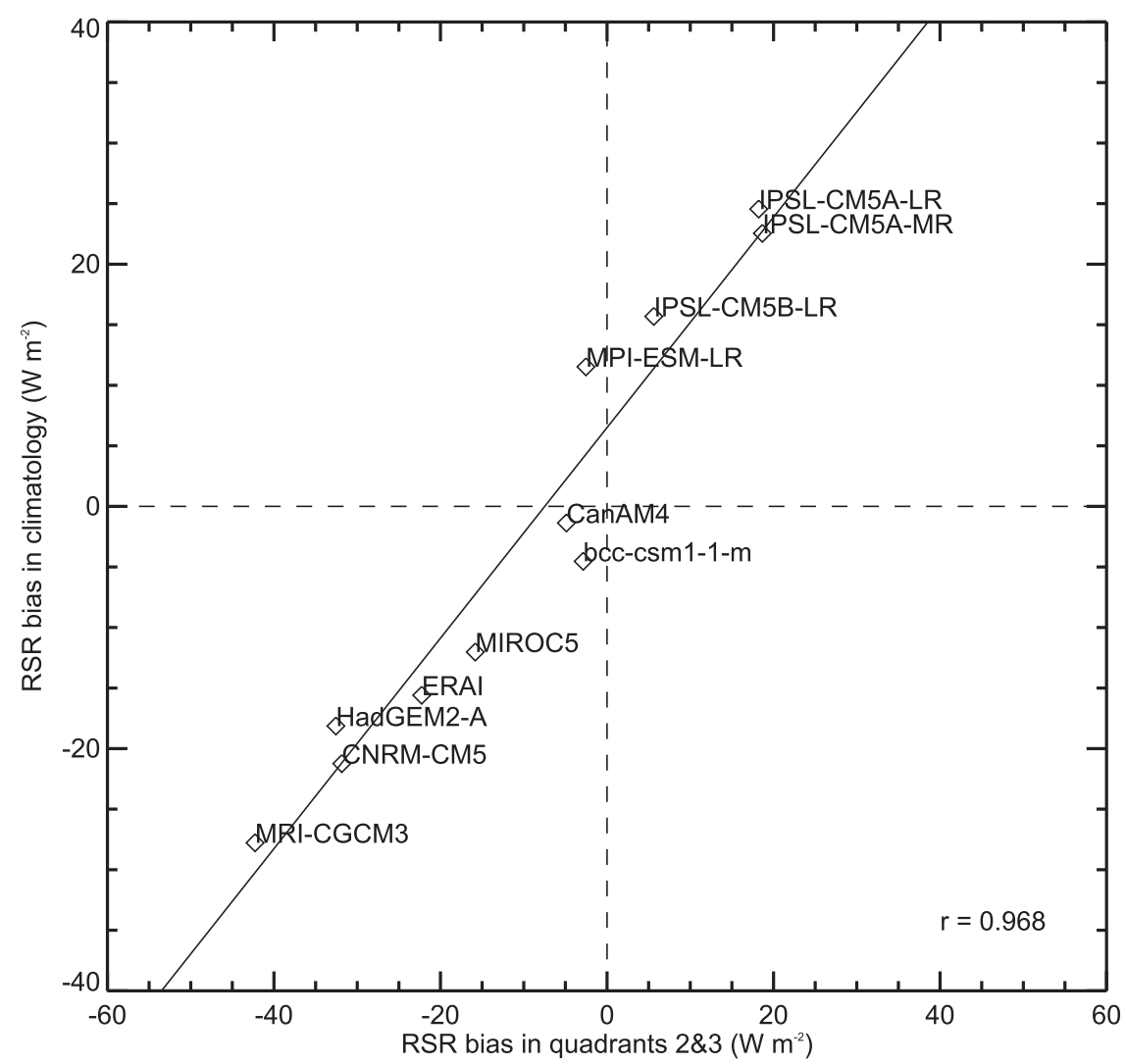

FIG. 4. Scatterplot of the DJF-mean climatological RSR error in the second and third quadrants of the cyclone composite and the entire $40^{\circ}-70^{\circ} \mathrm{S}$ region. The quadrants are defined using the standard trigonometric convention, as in Fig. 3a2.

near the center of the composite. In some models, the low-cloud regimes dominate the error in the leading edge of the cold-air side of the cyclone, behind the cold front. Similar maps for the RFO (not shown) show that the pattern of errors is dominated by the pattern of errors in RFO, with models underestimating the RFO of the midlevel regime across the entire domain. Thus, the composite averages presented in Fig. 6 are representative, not just the result of compensation of spatial patterns of errors.

This result, however, has to be interpreted with caution. As the regime classification is based on cloud radiative properties, clouds with the wrong radiative properties may be projected onto a different regime, and their impact on the error will be through errors in the relative frequency of occurrence. The online supplementary material presents detailed information of the cyclone composite biases for each model. For each regime, composite maps of RFO, average RSR when the regime occurs, and contribution of each regime to the total RSR are plotted for ISCCP, CERES, and all the models. This may be helpful for those interested in the sources of the errors of a particular model, whereas Fig. 6 gives an overview of the common errors across models.

It is worth mentioning that we repeated the analysis using an equal-angle grid in the composite (not shown), as done previously by Bodas-Salcedo et al. (2012) and Williams et al. (2013). The results are independent of the type of grid used in the composite, which implies that the results presented here and those of previous studies are robust.

\section{Is the midlevel regime really midlevel cloud?}

ISCCP uses the brightness temperature of the infrared channel to estimate the cloud-top temperature, from which then cloud-top pressure is estimated using an atmospheric temperature profile from the Television Infrared Observation Satellite (TIROS) Operational Vertical Sounder (Rossow and Schiffer 1999). Marchand et al. (2010) show that three situations are largely responsible for the errors in the ISCCP retrieval of cloud-top pressure: low-level clouds under temperature inversions, 
TABLE 2. Contributions to the DJF-mean RSR biases over the Southern Ocean $\left(40^{\circ}-70^{\circ} \mathrm{S}\right)$ from cyclonic (cy) and noncyclonic (nc) grid boxes. Angle brackets denote area-weighted means, so $\left\langle\mathrm{RFO}_{\mathrm{cy}}\right\rangle \cdot\left\langle\mathrm{RSR}_{\mathrm{cy}}\right\rangle \neq\left\langle\mathrm{RFO}_{\mathrm{cy}} \cdot \mathrm{RSR}_{\mathrm{cy}}\right\rangle$. Values for the $\langle\mathrm{RFO}\rangle(\%),\langle\mathrm{RSR}\rangle$ $\left(\mathrm{W} \mathrm{m}^{-2}\right)$, and $\langle\mathrm{RFO} \cdot \mathrm{RSR}\rangle\left(\mathrm{W} \mathrm{m}^{-2}\right)$ are shown. The first row shows the absolute values for CERES, and the rows below show the differences of ISCCP, ERA-Interim, and the models with respect to CERES. As we use the ERA-Interim mean sea level pressure for CERES and ISCCP, the RFOs of these three datasets are identical by construction. The last row is the average of the model differences.

\begin{tabular}{|c|c|c|c|c|c|c|}
\hline Dataset & $\left\langle\mathrm{RFO}_{\mathrm{cy}}\right\rangle$ & $\left\langle\mathrm{RSR}_{\mathrm{cy}}\right\rangle$ & $\left\langle\mathrm{RFO}_{\mathrm{cy}} \cdot \mathrm{RSR}_{\mathrm{cy}}\right\rangle$ & $\left\langle\mathrm{RFO}_{\mathrm{nc}}\right\rangle$ & $\left\langle\mathrm{RSR}_{\mathrm{nc}}\right\rangle$ & $\left\langle\mathrm{RFO}_{\mathrm{nc}} \cdot \mathrm{RSR}_{\mathrm{nc}}\right\rangle$ \\
\hline CERES & 54 & 179 & 101 & 46 & 178 & 77 \\
\hline ISCCP & 0 & 11 & 6 & 0 & 12 & 5 \\
\hline ERA-Interim & 0 & -12 & -8 & 0 & -17 & -6 \\
\hline BCC-CSM1.1-M & -1 & -1 & 0 & 1 & -5 & -3 \\
\hline CanAM4 & -2 & 5 & -3 & 2 & 1 & 5 \\
\hline CNRM-CM5 & 0 & -20 & -13 & -0 & -25 & -9 \\
\hline HadGEM2-A & -1 & -15 & -12 & 1 & -21 & -5 \\
\hline IPSL-CM5A-LR & -6 & 27 & 2 & 6 & 26 & 26 \\
\hline IPSL-CM5A-MR & 1 & 26 & 15 & -1 & 24 & 10 \\
\hline IPSL-CM5B-LR & 5 & 20 & 16 & -5 & 17 & 2 \\
\hline MIROC5 & -1 & -8 & -8 & 1 & -14 & -4 \\
\hline MPI-ESM-LR & 3 & 15 & 10 & -3 & 11 & 3 \\
\hline MRI-CGCM3 & 1 & -27 & -15 & -1 & -27 & -12 \\
\hline Differences & 0 & 2 & -1 & 0 & -1 & 1 \\
\hline
\end{tabular}

multilayer clouds, and subpixel or broken low-level clouds. The first two of these three situations may make ISCCP report a spurious midlevel cloud. The low vertical resolution of the atmospheric temperature profiles used in cloud retrievals based on passive imagers like ISCCP tends to underestimate the strength of the inversion above low-level clouds (Garay et al. 2008). This makes the retrieval place the cloud top too high, introducing a low bias in cloud-top pressure. Multilayer situations where optically thin cirrus sits over optically thick low-level cloud are also problematic, as the cloudtop retrieval will report a cloud top at the height of the mean radiative temperature of the two layers, somewhere in between the high and low cloud. Some of the clouds in the midlevel regime should there be expected not actually to be clouds with tops at middle levels. As the previous analysis shows that this regime is the regime responsible for most of the radiative biases in models over the Southern Ocean, it is relevant to understand the types of clouds that make this regime. This information can then be used by modelers to direct development efforts to those cloud types that are responsible for the errors in the radiation fields.

We now use CALIPSO-GOCCP data to understand the cloud scenes within the midlevel ISCCP regime. GOCCP produces instantaneous profiles of the lidar scattering ratio (SR) at 480-m vertical resolution and $330-\mathrm{m}$ horizontal resolution. The SR is the ratio of the attenuated total backscatter measured by CALIOP to the attenuated molecular backscatter that would be measured in the presence of a pristine atmosphere, without clouds or aerosols. Those volumes with SR $>5$ are classified as cloudy (for details, see Chepfer et al. 2010). We process 10 months of CALIPSO-GOCCP instantaneous data: the months of December, January, and February from December 2006 to December 2009. For each ISCCP $2.5^{\circ} \times 2.5^{\circ}$ grid box that contains $C A L I$ $P S O-G O C C P$ data, we calculate the CALIPSO-GOCCP cloud fraction in three layers (low, midlevel, and high). Then, we calculate the average cloud fraction in these three layers in the $40^{\circ}-70^{\circ} \mathrm{S}$ band for each of the ISCCP cloud regimes. The heights of the boundaries that separate the three layers are kept constant, and we estimate them using the midlatitude summer standard atmosphere tabulated in Houghton (1986). The division between low and midlevel cloud $(680 \mathrm{hPa})$ is placed at $3.4 \mathrm{~km}$, and the one between midlevel and high cloud $(440 \mathrm{hPa})$ is placed at $6.8 \mathrm{~km}$. Below we analyze the sensitivity of the results to the height of the boundaries.

Figure 8 a shows the vertical distribution of cloud from $C A L I P S O-\mathrm{GOCCP}$ as a function of the cloud regime. When ISCCP reports clear sky, CALIPSO-GOCCP also reports clear sky most of the time. This suggests that the conservative threshold used in SR for flagging a volume as cloudy produces a sensitivity quite similar to the ISCCP retrieval. CALIPSO-GOCCP reports that ISCCP low-level cloud regimes (shallow cumulus, transition, and stratocumulus) are indeed dominated by lowlevel cloud, with some contamination of cloud at higher levels. It is worth noting that the ISCCP cloud regimes are obtained from daily data, so a certain degree of contamination is always expected because of the time evolution of the cloud field and the spatial variability within the ISCCP grid box. Similarly, CALIPSO-GOCCP 

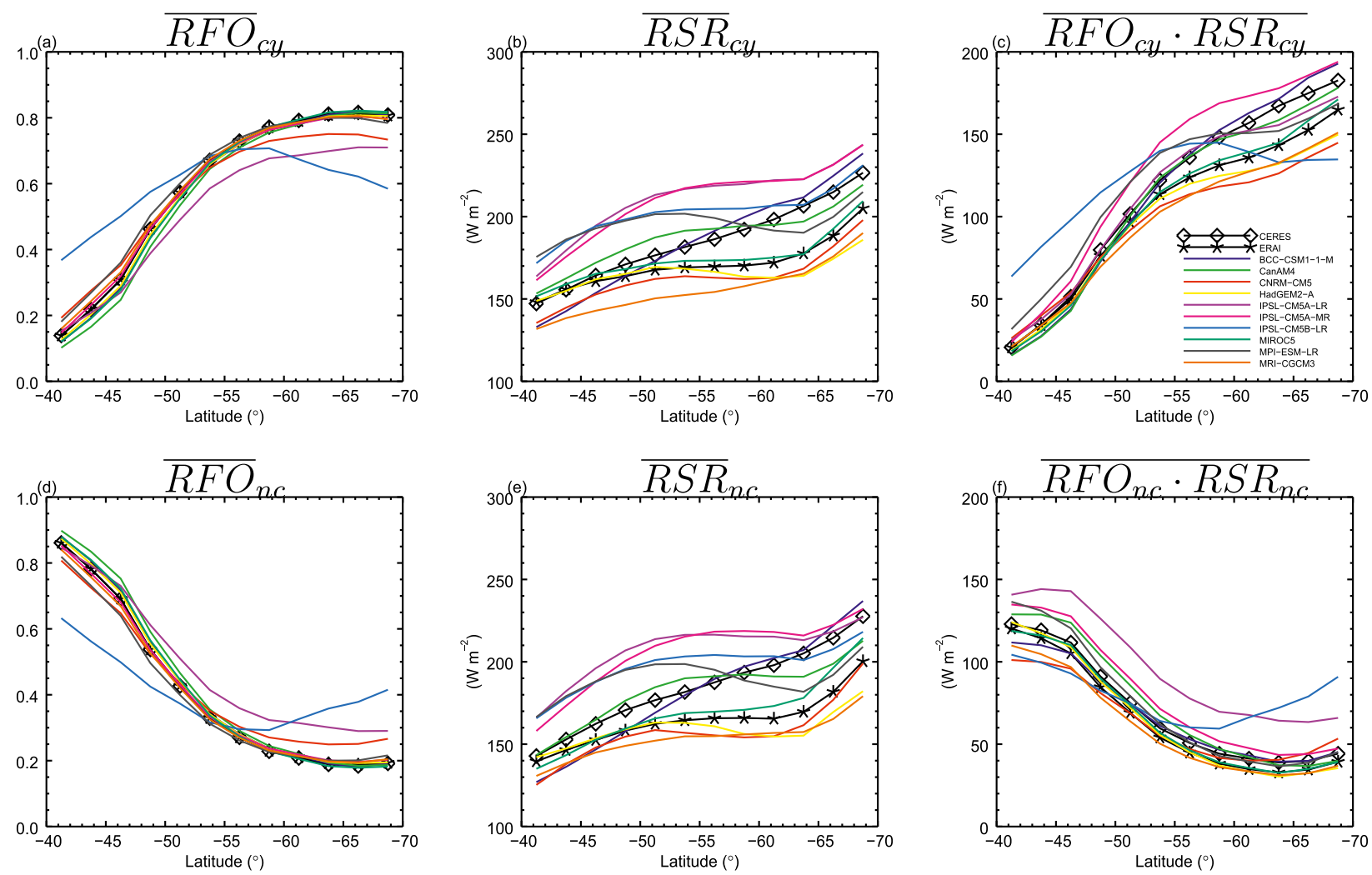

FIG. 5. Zonally averaged DJF means of cyclonic and noncyclonic points in the Southern Ocean $\left(40^{\circ}-70^{\circ} \mathrm{S}\right)$ : (a) fractional area occupied by cyclones, (b) mean RSR in cyclonic grid boxes, (c) contribution to the climatological-mean RSR from cyclonic grid boxes, (d) fractional area occupied by noncyclonic grid boxes, (e) mean RSR in noncyclonic grid boxes, and (f) contribution to the climatological-mean RSR from noncyclonic grid boxes. The overlines denote linear averages along latitude circles.

reports that the high-level cloud fraction is large in the high-level cloud regimes (frontal, cirrus, and thin cirrus). The fact that CALIPSO-GOCCP also shows a substantial amount of cloud at lower levels is not necessarily indicative of misclassification by ISCCP, as CALIPSO is able to penetrate through ice clouds. The midlevel regime shows cloud at all levels. The fact that the low-level cloud fraction in this regime is larger than the midlevel is an indication of misclassification in the ISCCP retrievals. Figure $8 \mathrm{~b}$ shows the percentage distribution of the ISCCP regimes that went into the results shown in Fig. 8 a. The number of $2.5^{\circ} \times 2.5^{\circ}$ grid boxes reported as clear by ISCCP is negligible. The midlevel regime is the most common regime, being reported nearly $40 \%$ of the time, followed by the stratocumulus regime, with more than $20 \%$. The other regimes have populations between $5 \%$ and $15 \%$, except for the thin cirrus with less than $5 \%$.

We now analyze the midlevel regime in more detail. For each grid box classified in the ISCCP midlevel regime, we classify each CALIPSO-GOCCP profile in one of eight possible classes, given by the possible combinations of the cloud occurring in any of the three layers. Figure $8 \mathrm{c}$ shows the percentage of population in each class, which we label $\mathrm{C} 1-\mathrm{C} 8$. The diagram at the bottom of the $x$ axis is a visual schematic of each class, where white means no cloud in that layer and gray means that the layer is cloudy. For instance, class $\mathrm{C} 1$ is the percentage of CALIPSO-GOCCP profiles in the midlevel regime that report no cloud in all three layers, and $\mathrm{C} 4$ shows the percentage of profiles that report cloud in the low and midlevel layers but not in the upper layer. $C A L I P S O-\mathrm{GOCCP}$ report that around $8 \%$ of the profiles are cloud free, consistent with the mean ISCCP cloud cover of that regime, 93\% (Williams and Webb 2009). CALIPSO-GOCCP sees only low-level cloud in such profiles around $35 \%$ of the time (class C2) and clouds with top at midlevel around $25 \%$ of the time (classes $\mathrm{C} 3$ and $\mathrm{C} 4$ ). The class with high-cloud above low-level cloud (C6) is reported $10 \%$ of the time. Profiles with clouds either at the two upper layers or in all three layers are reported the remaining $20 \%$ of the time (classes C7 and C8). Some of the profiles in C7 and C8 may actually be true ISCCP midlevel cloud, as the cloud 


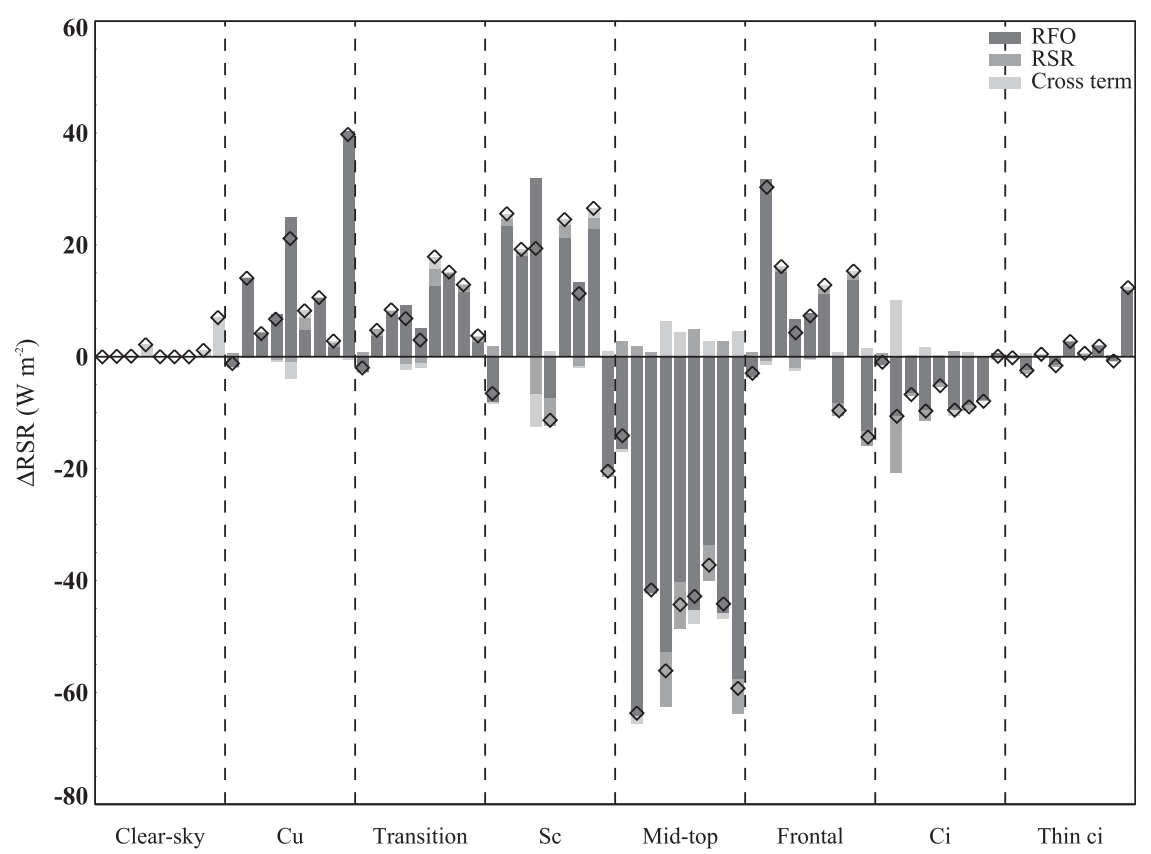

FIG. 6. Contribution of each cloud regime to the total error (model minus CERES) in the simulation of TOA RSR in the cyclone composite. The bars in each regime show results from left to right: ISCCP, BCC-CSM1.1-M, CanAM4, CNRM-CM5, HadGEM2-A, MIROC5, MPI-ESM-LR, and MRI-CGCM3. The total error in each regime is represented by the diamonds. The bars show a decomposition of the total error into contributions from errors in the RFO, the radiative properties of the regime when simulated (RSR), and a covariation term (cross term).

top estimated from infrared emission is below the real cloud top because of the diffuse tops of ice clouds (Weisz et al. 2007; Menzel et al. 2008).

Overall, it seems clear from this comparison that the retrieval error that dominates the misclassification of cloud into the ISCCP midlevel regime is that of lowlevel clouds under temperature inversions. This is consistent with the findings of Rossow and Zhang (2010), who show that in summer over the southern midlatitude oceans ISCCP has a low bias in cloud-top pressure when compared with active instruments. It is worth noting that the mean CTP- $\tau$ histogram of the midlevel regime, from which the centroid for the regime is computed, contains clouds with tops at other levels [see Fig. 3 of supplementary material in Williams and Webb (2009)]. We would therefore expect to see clouds with tops in the lower and upper layers even with a perfect retrieval. The results in Fig. $8 \mathrm{c}$ are robust with respect to changes in the height of the division between cloud layers applied to CALIPSO-GOCCP. The error bars in Fig. 8c show the sensitivity of the results to moving the height of the division between low-level and midlevel cloud by $\pm 480 \mathrm{~m}$ (one CALIPSO-GOCCP vertical level). This is a much larger variation than the change in geopotential height of the 680 -hPa pressure surface between $40^{\circ}$ and $70^{\circ}$ latitude in a standard midlatitude summer atmosphere. Mace (2010) calculates the vertical frequency distributions for CTP $-\tau$ classes used by ISCCP for a region over the Southern Ocean. An estimate of the percentage of clouds in the midlevel category $(440<\mathrm{CTP}<680 \mathrm{hPa})$ with tops lower than $3.2 \mathrm{~km}$ from Fig. 12 in Mace (2010) gives a value of $39 \%$, which is also consistent with the results presented here.

We have not made any attempt to quantify the radiative impact of the different cloud classes in the midlevel regime. However, Govekar et al. (2011) study the threedimensional distribution of clouds in cyclones in the Southern Hemisphere using CALIPSO and CloudSat data. They show that midlevel cloud fraction has a local maximum in the fourth quadrant of the cyclone composite, whereas low-level cloud spreads over the second, third, and fourth quadrants. This, as well as the fact that the mean RSR when the midlevel regime exists shows little spatial variability in the cyclone composite (see supplementary information), suggests that the albedos of classes $\mathrm{C} 2, \mathrm{C} 3$, and $\mathrm{C} 4$ are quite similar. Therefore, the differences in shortwave radiative impact of the different classes will be roughly proportional to the 
(a)BCC-CSM1-1-M

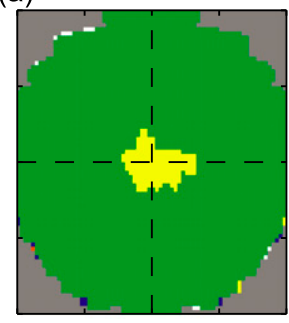

(f)

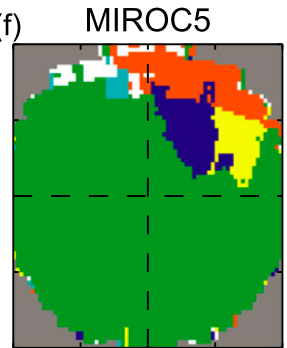

(b) CanAM4

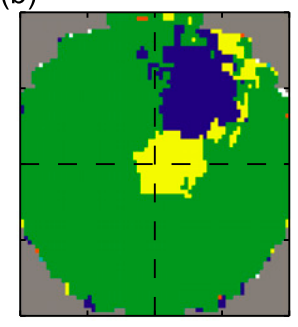

(g)

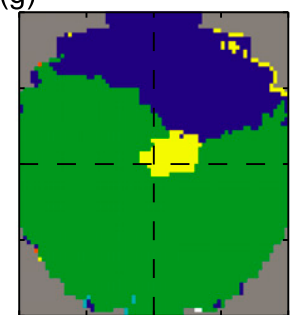

(c) CNRM-CM5

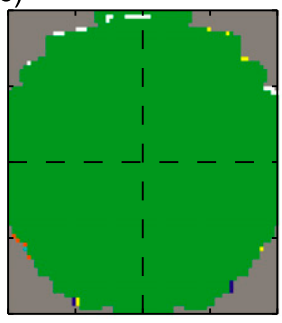

(h) MRI-CGCM3

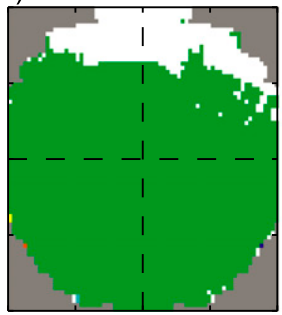

(d) HadGEM2-A

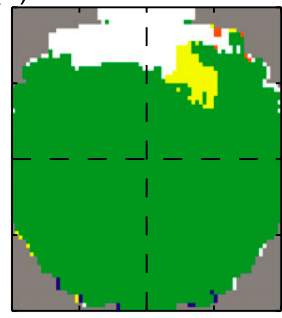

(e) IPSL-CM5B-LR

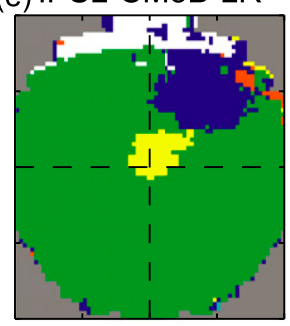

sha trs scu mdl frt cir tci

FIG. 7. Cloud regime with the largest absolute contribution to the total RSR error in each grid box of the cyclone composite. The total error contains contributions from errors in the frequency of occurrence of the regime and in the average RSR when the regime occurs. The labels in the color bar correspond to the seven cloud regimes: shallow cumulus, transition, stratocumulus, midlevel, frontal, cirrus, and thin cirrus.

differences in their frequency of occurrence within the regime. As mentioned above, models underestimate the $\mathrm{RFO}$ of the midlevel regime across the entire domain, which implies that classes $\mathrm{C} 2, \mathrm{C} 3$, and $\mathrm{C} 4$ all contribute to the errors in the radiative fluxes.

\section{Conclusions}

The current generation of climate models tends to reflect too little solar radiation over the Southern Ocean. It has been proposed that this surplus of solar energy absorbed in the Southern Hemisphere midlatitudes is a leading cause of the warm sea surface temperature (SST) biases in climate models. We study the role of clouds in the Southern Ocean's solar radiation budget in the atmosphere-only simulations of the Cloud Feedback Model Intercomparison Project phase 2 (CFMIP2), as they may have a leading role in controlling the solar radiation that is absorbed by the climate system in those latitudes. It is important to minimize the errors in atmosphere-only models to facilitate their coupling with ocean models, as these biases in the surface radiation budget will introduce biases in the coupled SSTs. Also, it is simpler to isolate the causes of cloud biases in atmosphereonly models than in coupled models.

To better understand the causes of these biases, we composite daily data around cyclone centers in the latitude band between $40^{\circ}$ and $70^{\circ} \mathrm{S}$ during summer. In most models, the cold-air sector shows a negative RSR bias, whereas the warm sector shows either a much smaller negative bias or a positive bias. Biases in cyclones dominate the climatological biases south of $55^{\circ} \mathrm{S}$, and this region in turn dominates the biases over $40^{\circ}-70^{\circ} \mathrm{S}$.

We then use the Williams and Webb (2009) method to classify daily-mean data into different cloud regimes and composite the cloud regimes around cyclone centers. This allows us to relate the cloud regimes and their associated radiative biases with the meteorological conditions in which they occur. The results show that the regime labeled as "midlevel" is the main contributor to RSR biases and dominate the error in most of the domain of the cyclone composite.

Further analysis with CALIPSO-GOCCP data shows that the midlevel regime is dominated by two main cloud classes: cloud with tops at midlevel and low-level cloud misclassified as midlevel. Based on the spatial pattern of the radiative effect of the midlevel regime, both classes contribute to the observe RSR biases. Williams et al. (2013) propose a potential mechanism for models to show a negative RSR bias in those regions in the cyclone composite occupied by low-level cloud. They analyze a case study that is typical of the bias and suggest that the coarse vertical resolution in the boundary layer in these models hinders their ability to properly represent the position and strength of the inversion, which tends to be too low and weak. This limits the ability to accurately represent boundary layer clouds, which affects the radiative cooling at the top of the boundary layer. This feeds back into the strength of the inversion and the evolution of the boundary layer, which becomes shallower 
(a)CALIPSO-GOCCP layer cloud fraction on ISCCP clusters

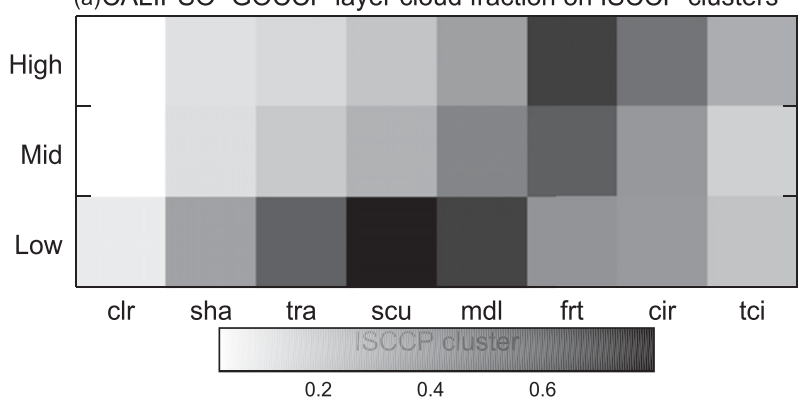

(b) Percentage of points in each regime
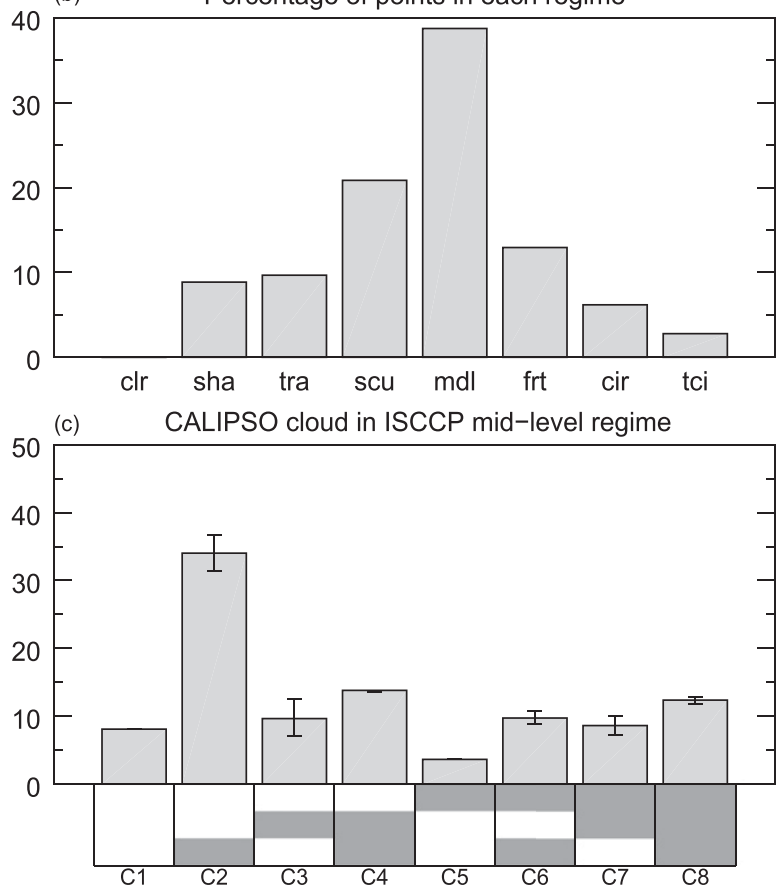

FIG. 8. Vertical distribution of clouds over the Southern Ocean from CALIPSO-GOCCP: (a) vertical distribution of cloud cover (\%) from CALIPSO in each ISCCP regime, (b) frequency distribution of the relative population of the ISCCP regimes of the grid boxes used in (a), and (c) percentage of CALIPSO-GOCCP profiles in the midlevel regime for each of the eight cloud classes (C1-C8) depicted in the schematic below the $x$ axis. In that schematic, white implies a cloud-free layer and gray implies a cloudy layer. Only CALIPSO-GOCCP profiles with nonattenuated volumes in the three layers are used. The error bars in (c) show the sensitivity to moving the height of the division between low-level and midlevel cloud by $\pm 480 \mathrm{~m}$ (one CALIPSO-GOCCP vertical level).

and thins the cloud further. The potential role of clouds with tops at midlevel (either congestus cloud or stratiform cloud at midlevels) and multilayer situations in the RSR biases is less well understood. Future work will focus on quantifying the role of these clouds in the radiation budget over the Southern Ocean. This should help elucidate the relative contribution of these situations to the solar radiation budget over the Southern Ocean.
Acknowledgments. We thank two anonymous reviewers for providing constructive comments that improved the quality of the paper. We thank H. Douville for providing comments and S. Tyteca for producing the data from the CNRM-CM5 model. Special thanks to $\mathrm{W}$. Ingram for helping to make the manuscript clearer. This work was supported by the Joint DECC/Defra Met Office Hadley Centre Climate Programme (GA01101). This work was funded by the European Union Seventh Framework Programme (FP7/2007-2013) under Grant Agreement 244067 via the EU Cloud Intercomparison and Process Study Evaluation project (EUCLIPSE). We acknowledge the World Climate Research Programme's Working Group on Coupled Modelling, which is responsible for CMIP, and we thank the climate modeling groups (listed in Table 1) for producing and making available their model output. For CMIP, the U.S. Department of Energy's Program for Climate Model Diagnosis and Intercomparison provides coordinating support and led development of software infrastructure in partnership with the Global Organization for Earth System Science Portals. ISCCP and CERES data were obtained from the NASA Langley Research Center Atmospheric Sciences Data Center (http://eosweb.larc. nasa.gov). ERA-Interim data used in this study were obtained from the ECMWF data server (http://dataportal.ecmwf.int/). CALIPSO-GOCCP data were obtained from the IPSL ClimServ data center (http:// climserv.ipsl.polytechnique.fr/cfmip-obs.html).

\section{REFERENCES}

Bauer, M., and A. D. Del Genio, 2006: Composite analysis of winter cyclones in a GCM: Influence on climatological humidity. J. Climate, 19, 1652-1672.

Bodas-Salcedo, A., and Coauthors, 2011: COSP: Satellite simulation software for model assessment. Bull. Amer. Meteor. Soc., 92, 1023-1043.

— K. D. Williams, P. R. Field, and A. P. Lock, 2012: The surface downwelling solar radiation surplus over the Southern Ocean in the Met Office model: The role of midlatitude cyclone clouds. J. Climate, 25, 7467-7486.

Bouttes, N., J. M. Gregory, T. Kuhlbrodt, and T. Suzuki, 2012: The effect of windstress change on future sea level change in the Southern Ocean. Geophys. Res. Lett., 39, L23602, doi:10.1029/ 2012 GL054207.

Caldeira, K., and P. B. Duffy, 2000: The role of the Southern Ocean in uptake and storage of anthropogenic carbon dioxide. Science, 287, 620-622, doi:10.1126/science.287.5453.620.

Ceppi, P., Y.-T. Hwang, D. M. W. Frierson, and D. L. Hartmann, 2012: Southern Hemisphere jet latitude biases in CMIP5 models linked to shortwave cloud forcing. Geophys. Res. Lett., 39, L19708, doi:10.1029/2012GL053115.

Chepfer, H., S. Bony, D. Winker, G. Cesana, J.-L. Dufresne, P. Minnis, C. J. Stubenrauch, and S. Zeng, 2010: The GCMOriented CALIPSO Cloud Product (CALIPSO-GOCCP) J. Geophys. Res., 115, D00H16, doi:10.1029/2009JD012251. 
Collins, W. J., and Coauthors, 2011: Development and evaluation of an earth-system model-HadGEM2. Geosci. Model Dev., 4, 1051-1075, doi:10.5194/gmd-4-1051-2011.

Dee, D. P., and Coauthors, 2011: The ERA-Interim reanalysis: Configuration and performance of the data assimilation system. Quart. J. Roy. Meteor. Soc., 137, 553-597, doi:10.1002/qj.828.

Field, P. R., and R. Wood, 2007: Precipitation and cloud structure in midlatitude cyclones. J. Climate, 20, 233-254.

- A. Gettelman, R. B. Neale, R. Wood, P. J. Rasch, and H. Morrison, 2008: Midlatitude cyclone compositing to constrain climate model behavior using satellite observations. J. Climate, 21, 5887-5903.

_- A. Bodas-Salcedo, and M. E. Brooks, 2011: Using model analysis and satellite data to assess cloud and precipitation in midlatitude cyclones. Quart. J. Roy. Meteor. Soc., 137, 15011515, doi:10.1002/qj.858.

Garay, M. J., S. P. de Szoeke, and C. M. Moroney, 2008: Comparison of marine stratocumulus cloud top heights in the southeastern Pacific retrieved from satellites with coincident ship-based observations. J. Geophys. Res., 113, D18204, doi:10.1029/2008JD009975.

Gent, P. R., and Coauthors, 2011: The Community Climate System Model version 4. J. Climate, 24, 4973-4991.

Gleckler, P. J., 2005: Surface energy balance errors in AGCMs: Implications for ocean-atmosphere model coupling. Geophys. Res. Lett., 32, doi:10.1029/2005GL023061.

Govekar, P. D., C. Jakob, M. J. Reeder, and J. Haynes, 2011: The three-dimensional distribution of clouds around Southern Hemisphere extratropical cyclones. Geophys. Res. Lett., 38, L21805, doi:10.1029/2011GL049091.

Haynes, J. M., C. Jakob, W. B. Rossow, G. Tselioudis, and J. Brown, 2011: Major characteristics of Southern Ocean cloud regimes and their effects on the energy budget. J. Climate, 24, 5061-5080.

Holland, P. R., A. Jenkins, and D. M. Holland, 2010: Ice and ocean processes in the Bellingshausen Sea, Antarctica. J. Geophys. Res., 115, C05020, doi:10.1029/2008JC005219.

Houghton, J. T., 1986: The Physics of Atmospheres. Cambridge University Press, $271 \mathrm{pp}$.

Hourdin, F., and Coauthors, 2013a: Impact of the LMDZ atmospheric grid configuration on the climate and sensitivity of the IPSL-CM5A coupled model. Climate Dyn., 40, 2167-2192, doi:10.1007/s00382-012-1411-3.

— nent of the IPSL climate model with revisited parameterizations for clouds and convection. Climate Dyn., 40, 2193-2222, doi:10.1007/s00382-012-1343-y.

Hwang, Y.-T., and D. M. W. Frierson, 2013: Link between the double-intertropical convergence zone problem and cloud biases over the Southern Ocean. Proc. Natl. Acad. Sci. USA, 110, 4935-4940, doi:10.1073/pnas.1213302110.

Jakob, C., and G. Tselioudis, 2003: Objective identification of cloud regimes in the tropical western Pacific. Geophys. Res. Lett., 30, 2082, doi:10.1029/2003GL018367.

Klein, S. A., and C. Jakob, 1999: Validation and sensitivities of frontal clouds simulated by the ECMWF model. Mon. Wea. Rev., 127, 2514-2531.

Kuhlbrodt, T., and J. M. Gregory, 2012: Ocean heat uptake and its consequences for the magnitude of sea level rise and climate change. Geophys. Res. Lett., 39, L18608, doi:10.1029/ 2012GL052952.

Loeb, N. G., B. A. Wielicki, D. R. Doelling, S. Kato, T. Wong, G. L. Smith, D. F. Keyes, and N. Manalo-Smith, 2009: Toward optimal closure of the earth's top-of-atmosphere radiation budget. J. Climate, 22, 748-766.

Mace, G. G., 2010: Cloud properties and radiative forcing over the maritime storm tracks of the Southern Ocean and North Atlantic derived from A-Train. J. Geophys. Res., 115, D10201, doi:10.1029/2009JD012517.

Marchand, R., T. Ackerman, M. Smythe, and W. B. Rossow, 2010: A review of cloud top height and optical depth histograms from MISR, ISCCP, and MODIS. J. Geophys. Res., 115, D16206, doi:10.1029/2009JD013422.

Marshall, J., and K. Speer, 2012: Closure of the meridional overturning circulation through Southern Ocean upwelling. Nat. Geosci., 5, 171-180, doi:10.1038/ngeo1391.

Martin, G. M., and Coauthors, 2011: The HadGEM2 family of Met Office Unified Model climate configurations. Geosci. Model Dev., 4, 723-757, doi:10.5194/gmd-4-723-2011.

Menzel, W. P., and Coauthors, 2008: MODIS global cloud-top pressure and amount estimation: Algorithm description and results. J. Appl. Meteor. Climatol., 47, 1175-1198.

Mizuta, R., and Coauthors, 2012: Climate simulations using MRIAGCM3.2 with 20-km grid. J. Meteor. Soc. Japan, 90A, 233258, doi:10.2151/jmsj.2012-A12.

Oreopoulos, L., and W. B. Rossow, 2011: The cloud radiative effects of International Satellite Cloud Climatology Project weather states. J. Geophys. Res., 115, D12202, doi:10.1029/ 2010JD015472.

Rossow, W. B., and R. A. Schiffer, 1999: Advances in understanding clouds from ISCCP. Bull. Amer. Meteor. Soc., 80, 2261-2287.

- and Y. Zhang, 2010: Evaluation of a statistical model of cloud vertical structure using combined CloudSat and CALIPSO cloud layer profiles. J. Climate, 23, 6641-6653.

- G. Tselioudis, A. Polak, and C. Jakob, 2005: Tropical climate described as a distribution of weather states indicated by distinct mesoscale cloud property mixtures. Geophys. Res. Lett., 32, L21812, doi:10.1029/2005GL024584.

Rotstayn, L. D., M. A. Collier, M. R. Dix, Y. Feng, H. B. Gordon, S. P. O'Farrell, I. N. Smith, and J. Syktus, 2010: Improved simulation of Australian climate and ENSO-related rainfall variability in a global climate model with an interactive aerosol treatment. Int. J. Climatol., 30, 1067-1088, doi:10.1002/joc.1952.

Stephens, G. L., and Coauthors, 2002: The CloudSat mission and the A-Train. Bull. Amer. Meteor. Soc., 83, 1771-1790.

$\mathrm{Su}, \mathrm{H}$., and Coauthors, 2013: Diagnosis of regime-dependent cloud simulation errors in CMIP5 models using A-Train satellite observations and reanalysis data. J. Geophys. Res., 118, 27622780, doi:10.1029/2012JD018575.

Taylor, K. E., R. J. Stouffer, and G. A. Meehl, 2012: An overview of CMIP5 and the experiment design. Bull. Amer. Meteor. Soc., 93, 485-498.

Trenberth, K. E., and J. T. Fasullo, 2010: Simulation of present-day and twenty-first-century energy budgets of the southern oceans. J. Climate, 23, 440-454.

Tselioudis, G., and W. B. Rossow, 2011: Time scales of variability of the tropical atmosphere derived from cloud-defined weather states. J. Climate, 24, 602-608.

,$- \ldots$, Y. Zhang, and D. Konsta, 2013: Global weather states and their properties from passive and active satellite cloud retrievals. J. Climate, 26, 7734-7746.

Tsushima, Y., M. A. Ringer, M. J. Webb, and K. D. Williams, 2013: Quantitative evaluation of the seasonal variations in climate model cloud regimes. Climate Dyn., doi:10.1007/ s00382-012-1609-4, in press. 
Voldoire, A., and Coauthors, 2013: The CNRM-CM5.1 global climate model: Description and basic evaluation. Climate Dyn., 40, 2091-2121, doi:10.1007/s00382-011-1259-y.

Volodin, E. M., N. A. Dianskii, and A. V. Gusev, 2010: Simulating present-day climate with the INMCM4.0 coupled model of the atmospheric and oceanic general circulations. Izv. Atmos. Oceanic Phys., 46, 414-431, doi:10.1134/S000143381004002X.

von Salzen, K., and Coauthors, 2013: The Canadian fourth generation atmospheric global climate model (CanAM4). Part I: Representation of physical processes. Atmos.-Ocean, 51, 104 125, doi:10.1080/07055900.2012.755610.

Watanabe, M., and Coauthors, 2010: Improved climate simulation by MIROC5: Mean states, variability, and climate sensitivity. J. Climate, 23, 6312-6335.

Webb, M., C. Senior, S. Bony, and J. J. Morcrette, 2001: Combining ERBE and ISCCP data to assess clouds in the Hadley Centre, ECMWF and LMD atmospheric climate models. Climate Dyn., 17, 905-922.

Weisz, E., J. Li, W. P. Menzel, A. K. Heidinger, B. H. Kahn, and C.-Y. Liu, 2007: Comparison of AIRS, MODIS, CloudSat and CALIPSO cloud top height retrievals. Geophys. Res. Lett., 34, L17811, doi:10.1029/2007GL030676.

Wielicki, B., B. R. Barkstrom, E. F. Harrison, R. B. Lee III, G. L. Smith, and J. E. Cooper, 1996: Clouds and the Earth's Radiant Energy System (CERES): An Earth Observing System experiment. Bull. Amer. Meteor. Soc., 77, 853-868.

Williams, K. D., and G. Tselioudis, 2007: GCM intercomparison of global cloud regimes: Present-day evaluation and climate change response. Climate Dyn., 29, 231-250, doi:10.1007/ s00382-007-0232-2.

—, and M. E. Brooks, 2008: Initial tendencies of cloud regimes in the Met Office Unified Model. J. Climate, 21, 833-840.

- and M. J. Webb, 2009: A quantitative performance assessment of cloud regimes in climate models. Climate Dyn., 33, 141-157, doi:10.1007/s00382-008-0443-1.

_ , and Coauthors, 2013: The Transpose-AMIP II experiment and its application to the understanding of Southern Ocean cloud biases in climate models. J. Climate, 26, 3258-3274.

Winker, D. M., M. A. Vaughan, A. Omar, Y. Hu, K. A. Powell, Z. Liu, W. H. Hunt, and S. A. Young, 2009: Overview of the CALIPSO mission and CALIOP data processing algorithms. J. Atmos. Oceanic Technol., 26, 2310-2323.

$\mathrm{Wu}, \mathrm{T}$., and Coauthors, 2010: The Beijing Climate Center atmospheric general circulation model: Description and its performance for the present-day climate. Climate Dyn., 34, 123-147, doi:10.1007/s00382-008-0487-2.

Yukimoto, S., and Coauthors, 2011: Meteorological Research Institute-Earth System Model Version 1 (MRI-ESM1): Model description. Meteorological Research Institute Tech. Rep. 64, $96 \mathrm{pp}$.

Zhang, Y., W. B. Rossow, A. A. Lacis, V. Oinas, and M. I. Mishchenko, 2004: Calculation of radiative fluxes from the surface to top of atmosphere based on ISCCP and other global data sets: Refinements of the radiative transfer model and input data. J. Geophys. Res., 109, D19105, doi:10.1029/ 2003JD004457. 